\title{
Using EPIC Model to Determine a Sustainable Potato/Cereal Cropping System in the Arid Region of the Loess Plateau of China
}

\author{
Xuechun Wang ${ }^{1, *}$, Jun $\mathrm{Li}^{2}$, and Shishun Tao ${ }^{1}$ \\ ${ }^{1}$ School of Life Science and Technology, Southwest University of Science and Technology, \\ Mianyang, Sichuan, 621010, China; \\ xuechunwang@swust. edu.cn \\ ${ }^{2}$ College of Agronomy, Northwest A \& F University, Yangling, Shaanxi 712100, China
}

\begin{abstract}
Potato has become one of the primary cash crops in the arid region of the Loess Plateau. However, what and how cereal crops to rotate with potato is better for the farmer's income and environment is unclear now. 11 potato based rotation systems were simulated in Yulin, using EPIC model based on local information. Results showed 1) Though mean potato yield decreased from 6.84 to $5.38 \mathrm{t} / \mathrm{hm}^{2}$, the mean value of farmer's gross income increased from 12807 to $20185 \mathrm{Yuan} / \mathrm{hm}^{2}$, when the frequency of potato increased from 0.25 to 0.50 for potato based rotation sequence. 2) By comparing, spring maize was better to increase potato yield, while it used more water than foxtail millet and broomcorn millet; Foxtail millet was one of the better preceding crops for potato, and its effects on potato yield was depended on its sequence in potato based rotation system. 3) Comparing with spring maize/potato system, foxtail millet/potato and spring maize/potato/foxtail millet/potato were two better rotation systems to use soil water sustainably and to increase farmer's gross income for a long period in the arid region of the Loess Plateau.
\end{abstract}

Keywords: The Loess Plateau, Arid region, Potato, Rotation, EPIC model.

\section{Introduction}

Potato has become one of the primary cash crops in the arid regions of the Loess Plateau. As a shallow root crop, potato uses less water than other deep root crops [1]. This character increased farmer's interest to plant potato in the arid areas (annual rainfall was not more than $450 \mathrm{~mm}$ ) of the Loess Plateau. Another reason is the great difference of temperature $\left(10-16^{\circ} \mathrm{C}\right)$ between day and night is better to accumulate more dry material for potato in the north region of the Loess Plateau. According statistical data [2], potato has been planted more than $2.4 \times 10^{5} \mathrm{hm}^{2}$ (33\% of the grain crop planting area), and contributed about $26.7 \%$ of total agricultural cash receipts in Shaaxi Province of China.

\footnotetext{
* Corresponding author.

D. Li and Y. Chen (Eds.): CCTA 2012, Part II, IFIP AICT 393, pp. 60-68, 2013.

(C) IFIP International Federation for Information Processing 2013
} 
However agricultural technology of potato production still needs to improve in the arid region of the Loess Plateau. Liu [3] and Li [4] reported that potential yield of potato in northern Shaanxi was more than $15 \mathrm{t} / \mathrm{hm}^{2}$ ), however actual potato yield in the field was less than $5.9 \mathrm{t} / \mathrm{hm}^{2}$ [5]. Most reports believed that rotating with cereal crops was one of the better agricultural technologies to increase potato yield [6]. Over the years, increasing costs of acquiring suitable agricultural land and irrigation equipment promoted many farmers to limit rotation of other crops with potatoes. Now, spring maize/potato and broomcorn millet/potato have become the primary potato based agricultural systems in the arid region of the Loess Plateau. However If the present potato-grain rotation system was reasonable, what crop and what sequence of such crop is reasonable and sustainable are still not clear in the arid region of the Loess Plateau.

Field experiment is a better and direct method to determine a sustainable potato-cereal rotation sequence. However, it is a long-term endeavor that is both expensive and time-consuming. With the development of crop model, using computer model to simulate soil water content and crop yield based on local information has become another better approach to answer this question. One such model is the EPIC model which simulates soil water and crop yield simultaneously under the help of its two sub models (growth model and hydrology model). Wang and Li reported that EPIC model can estimate soil water and crop yield well with the new database for the Loess Plateau[1].

Objectives of this paper were to determine a sustainable potato/cereal cropping system in the arid region of the Loess Plateau, and to point out some advices for farmers in the homogeneous areas of the world.

\section{$1 \quad$ Material and Method}

\subsection{Site Description}

Yulin $\left(107.5 \sim 111.3^{\circ} \mathrm{E}, 36.9 \sim 39.6^{\circ} \mathrm{N}\right)$, as a northern city of Shaanxi Province in China, is located at the junction of the Loess Plateau and the Mu Us Desert. It is an arid continental monsoon climate zone and is a representative rain-fed area of China. Its mean annual precipitation is $400 \mathrm{~mm}$, with the mean annual temperature of $10^{\circ} \mathrm{C}$, and the mean frost-free period of $152 \mathrm{~d}$. Its predominant soil type, used for potato, is Miansha soil.

\subsection{Rotation Sequence}

11 potato based cropping systems (tale 1) were established based on the following information: 1) Potato was one of the primary cash crops for farmers in Yulin. 2) Foxtail millet and broomcorn millet were the main crops used to build rotation sequence in the arid region of the Loess Plateau. 3) Spring maize was the primary crop to produce food for farmers. Where spring maize/potato and broomcorn millet/potato were two widely practiced potato based agricultural system in Yulin. 
Table 1. Information for the simulated potato based rotation system in Yulin

\begin{tabular}{cll}
\hline group & Rotation system & Rotation sequence \\
\hline & $\mathrm{M} / \mathrm{M} / \mathrm{M} / \mathrm{P}$ & spring maize / spring maize / spring maize /potato \\
$\mathrm{M} / \mathrm{B} / \mathrm{M} / \mathrm{P}$ & spring maize / broomcorn millet/ spring maize /potato \\
$\mathrm{F} / \mathrm{M} / \mathrm{B} / \mathrm{P}$ & foxtail millet/ spring maize/ broomcorn millet/ potato \\
$\mathrm{M} / \mathrm{F} / \mathrm{M} / \mathrm{P}$ & spring maize/foxtail millet/ spring maize/potato \\
\hline $\mathrm{M} / \mathrm{M} / \mathrm{P}$ & spring maize / spring maize /potato \\
& $\mathrm{M} / \mathrm{F} / \mathrm{P}$ & spring maize / foxtail millet /potato \\
$\mathrm{M} / \mathrm{B} / \mathrm{P}$ & spring maize /broomcorn millet/potato \\
& $\mathrm{F} / \mathrm{B} / \mathrm{P}$ & foxtail millet/broomcorn millet/ potato \\
\hline \multirow{3}{*}{$\mathrm{M} / \mathrm{P}$} & spring maize /potato \\
& $\mathrm{F} / \mathrm{P}$ & foxtail millet /potato \\
$\mathrm{M} / \mathrm{P} / \mathrm{F} / \mathrm{P}$ & spring maize/ potato / foxtail millet /potato \\
\hline
\end{tabular}

\subsection{Method}

\subsubsection{Soil Moisture Grade}

In this research, based on Soil Desiccation Index (SDI)[7], soil moisture were classified into 6 grades (table 2). To build up a decision table for soil moisture grade, the range of soil water content for each soil moisture grade was calculated using equation 1 .

$$
\mathrm{MSW}=\mathrm{SDI} \times(\mathrm{SSM}-\mathrm{SWW})+\mathrm{SWW}
$$

Where MSW is Soil Water Content calculated from SDI, SSM and SWW. SDI is Soil Desiccation Index, SWW is Soil Water content at Wilting point, and SSM is Stable Soil Water content.

Table 2. Decision table of soil moisture grade for Miansha soil in Yulin

\begin{tabular}{ccc}
\hline Soil moisture grade & Soil water content by weight(SM) $(\%)$ & Soil Desiccation Index (SDI) \\
\hline I & $\mathrm{SM} \geq 14.0$ & $\mathrm{SDI} \geq 1.00$ \\
II & $14.0>\mathrm{SM} \geq 11.5$ & $1.00>\mathrm{SDI} \geq 0.75$ \\
III & $12.5>\mathrm{SM} \geq 11.0$ & $0.75>\mathrm{SDI} \geq 0.50$ \\
IV & $11.0>\mathrm{SM} \geq 9.5$ & $0.50>\mathrm{SDI} \geq 0.25$ \\
V & $9.5>\mathrm{SM} \geq 8.0$ & $0.25>\mathrm{SDI} \geq 0.00$ \\
VI & $\mathrm{SM}<8.0$ & $\mathrm{SDI}<0.00$ \\
\hline
\end{tabular}




\subsubsection{Potato Yield and Gross Income}

According calculating method used by State Statistics Bureau of China [2], potato yield was calculated into grain yield using equation 2 .

$$
\mathrm{Y}_{\mathrm{pc}}=0.2 \times \mathrm{Y}_{\mathrm{p}}
$$

Where $Y_{p c}$ was the potato yield calculated from fresh tuber yield of potato, $Y_{p}$ was the fresh tuber yield of potato.

Gross income for different cropping system was calculated by equation 3 based on the average price of spring maize, broomcorn millet, foxtail millet and fresh potato from 2001 to 2010.

$$
\mathrm{GI}=\sum_{\mathrm{t}=1}^{\mathrm{T}} \sum_{\mathrm{i}=1}^{\mathrm{I}}\left(P_{i} Y_{i t}-C_{i t}\right)
$$

Where GI was the gross income, $P_{i}$ was the average price of crop i from 2001 to 2010; $\mathrm{Y}_{\mathrm{it}}$ was the yield of crop $\mathrm{i}$ in year $\mathrm{t}$; $\mathrm{C}_{\mathrm{it}}$ was the variable costs associated with crop $\mathrm{i}$ in year t. Variable costs of different crops included expense for seed, plowing, fertilizer, seeding, operating machinery.

Effects of preceding crop on potato yield were calculated using equation 4.

$$
E_{i}=\frac{1}{N} \times \sum_{n=1}^{N} \frac{Y P_{i t}-Y_{p c}}{Y_{p c}}
$$

Where $\mathrm{N}$ was the times of potato planted after crop i during 1965 to 2000 . $\mathrm{YP}_{\mathrm{it}}$ was the potato yield after crop i in year $t$. $\mathrm{Y}_{\mathrm{pc}}$ was the actual mean potato yield in Yulin from 2008 to $2010\left(5.9 \mathrm{t} / \mathrm{hm}^{2}\right)$.

\section{Results}

\subsection{Crop Yield for Different Rotation Cropping Systems}

Taking mean yield and gross income into account, MMMP and MFMP were better rotation cropping system within group A. Mean potato yield of MFMP reduced $0.52 \mathrm{t} / \mathrm{hm}^{2}$ comparing with that of MMMP and increased 0.14 and $1.20 \mathrm{t} / \mathrm{hm}^{2}$ comparing with that of MBMP and FMBP. Mean maize yield of MFMP was $0.45 \mathrm{t} / \mathrm{hm}^{2}$ higher than that of FMBP, and was 0.10 and $0.05 \mathrm{t} / \mathrm{hm}^{2}$ lower than MMMP and MBMP. Mean broomcorn millet yield of MFMP increased 0.46t/hm ${ }^{2}$, comparing with that of FMBP. From 1965 to 2000, farmers got more gross income by MFMP rotation system, which increased $9.0 \%$ and $16.6 \%$ comparing with that by MBMP and FMBP. For MFMP rotation system, $8.4 \%$ of gross income produced by potato, which was higher than that of MMMP (6.0\%) and MBMP (6.6\%) rotation system and was lower than that of FMBP $(9.5 \%)$. 
MMP and MFP generated more yield and more gross income, comparing with other rotation systems within group B. MMP rotation system produced the highest yield of maize $\left(1.66 \mathrm{t} / \mathrm{hm}^{2}\right)$ and potato $\left(6.89 \mathrm{t} / \mathrm{hm}^{2}\right)$. From 1965 to 2000 , MMP cropping system generated the highest gross income of $16026 \mathrm{Yuan} / \mathrm{hm}^{2}$, MFP was the second with the value of $15321 \mathrm{Yuan} / \mathrm{hm}^{2}$. For MMP rotation system, potato contributed $89.7 \%$ of the gross income, which was significantly higher than that for MFP $(84.7 \%)$.

Within group C, MPFP rotation system got the highest yield of maize $\left(1.56 \mathrm{t} / \mathrm{hm}^{2}\right)$, foxtail millet $\left(1.89 \mathrm{t} / \mathrm{hm}^{2}\right)$ and potato $\left(6.00 \mathrm{t} / \mathrm{hm}^{2}\right)$. From 1965 to 2000 , gross income of spring maize, foxtail millet and potato in MPFP cropping system was 580, 1035, 18782 Yuan $/ \mathrm{hm}^{2}$ respectively, which was significantly higher than that in MP and FP cropping system. For MPFP cropping system, potato contributed $92.1 \%$ of the gross income, which was significantly higher than that for MP (94.8\%) and was significantly lower than that for FP $(90.0 \%)$.

\subsection{Effect of Preceding Crop on Potato Yield}

Effect of preceding crop on potato yield was affected by crop species and its rotation sequence in potato based cropping system (table 3). Effect index of spring maize on potato yield was the highest in MMMP rotation system, while was the lowest in MP rotation system. MFP was the best cropping system with the effect index value of 0.054 for foxtail millet to increase potato yield, however, effect index of foxtail millet in FP indicated that foxtail millet had a negative impacts on the production of potato yield. By comparing among all the simulated crops, as a preceding crop, spring maize was better to increase potato yield, while broomcorn millet has a negative impacts on potato yield.

Table 3. Effects of preceding crops on potato yield in different rotation systems in Yulin

\begin{tabular}{ccc}
\hline Preceding crops & Rotation sequence & Effect index of preceding crop \\
\hline \multirow{3}{*}{ Spring maize } & MMMP & 0.286 \\
& MFMP & 0.198 \\
& MMP & 0.168 \\
MBMP & 0.154 \\
Broomcorn millet & MP & -0.003 \\
\hline \multirow{3}{*}{ Foxtail millet } & FMBP & -0.005 \\
& FBP & -0.034 \\
& MBP & -0.049 \\
\hline & MFP & 0.054 \\
& MPFP & 0.017 \\
\hline
\end{tabular}




\subsection{Soil Water for Different Cropping Systems}

\subsubsection{Available Soil Water for Different Cropping Systems}

Different cropping systems have different capacity to use soil water in depth and extension, therefore, the difference of available soil water between different rotation system was significant. Mean available soil water in 0-10m soil were 1016, 1018 and $1034 \mathrm{~mm}$ for group A, group B and group C respectively. FMBP, FMP and FP was the best rotation system within group $\mathrm{A}$, group $\mathrm{B}$ and group $\mathrm{C}$ respectively, with the mean available soil water of 1039, 1073 and $1072 \mathrm{~mm}$ respectively .

Available soil water in $0-10 \mathrm{~m}$ soil reduced with the increasing of cultivation years of different rotation cropping systems in Yulin. Comparing with that during 1965-1976, available soil water in 0-10m soil during 1989-2000 reduced 250, 201, 161 and $197 \mathrm{~mm}$ for MMMP, MBMP, FMBP and MFMP respectively; 193, 187188 and 40mm for MMP, FMP, MBP and FBP respectively; 200, 47 and $171 \mathrm{~mm}$ for MP, FP and MPFP respectively. FP was the best cropping system to use soil water sustainably, with the lowest reducing of soil water from 1965 to 2000. FBP was the second and FMBP was the third rotation system, considering the sustainable use of soil water.

\subsubsection{Soil Water in Different Soil Layers for Different Cropping Systems}

Steady dry soil layers built in $2.0-4.0 \mathrm{~m}$ soil, and soil moisture changed with the change of rotation sequence and rainfall in different years. Steady dry soil layers built in 2.0-5.0 m soil for MMMP, MMP and MBMP cropping system, in 2.0-3.0 m soil for FP cropping system, in $2.0-4.0 \mathrm{~m}$ soil for other cropping systems (table 4 ).

Table 4. Stable dry soil layers and required years for soil moisture grade reach to $\mathrm{V}$ in different potato based rotation system in Yulin

\begin{tabular}{|c|c|c|c|c|c|c|c|}
\hline \multirow{2}{*}{$\begin{array}{c}\text { Rotati } \\
\text { on } \\
\text { patter } \\
n \\
\end{array}$} & \multicolumn{6}{|c|}{ Required years for soil moisture grade reached to $\mathrm{V}$} & \multirow{2}{*}{$\begin{array}{c}\text { Maximum } \\
\text { restored } \\
\text { soil } \\
\text { depth }(m)\end{array}$} \\
\hline & $\begin{array}{c}0-0.5 \\
\mathrm{~m}\end{array}$ & $\begin{array}{c}0.5-1.0 \\
\mathrm{~m}\end{array}$ & $1.0-2.0 \mathrm{~m}$ & $2.0-3.0 \mathrm{~m}$ & $3.0-4.0 \mathrm{~m}$ & $4.0-5.0 \mathrm{~m}$ & \\
\hline $\begin{array}{c}\text { MMM } \\
\text { P }\end{array}$ & - & 8 & 5 & 12 & 15 & 26 & $2-5$ \\
\hline $\begin{array}{c}\text { MBM } \\
\mathrm{P}\end{array}$ & - & 14 & 7 & 16 & 25 & 32 & $2-5$ \\
\hline FMBP & - & 18 & 12 & 22 & 30 & - & $2-4$ \\
\hline $\begin{array}{c}\text { MFM } \\
\text { P }\end{array}$ & - & 16 & 11 & 19 & 28 & - & $2-4$ \\
\hline MMP & - & 10 & 8 & 12 & 16 & 28 & $2-5$ \\
\hline MFP & - & 13 & 12 & 18 & 26 & - & $2-4$ \\
\hline
\end{tabular}


Table 4. (Continued)

\begin{tabular}{cccccccc}
\hline MBP & - & 15 & 10 & 17 & 24 & - & $2-4$ \\
FBP & - & 18 & 13 & 18 & 24 & - & $2-4$ \\
MP & - & 16 & 12 & 19 & 23 & - & $2-4$ \\
FP & - & 24 & 17 & 27 & - & - & $2-3$ \\
MPFP & 1 & 18 & 15 & 18 & 28 & - & $2-4$ \\
\hline
\end{tabular}

Crop specie was an important factor to impact the change of soil water for potato/cereal rotation system. Simulation results showed the depletion of soil water in spring maize field was maximum, in broomcorn millet field was the second, in foxtail millet field and potato field was the following. Soil water reduced in $0-1.5 \mathrm{~m}$ soil when potato or foxtail millet was planted, and it reduced in 0-2m soil when spring maize was planted.

Rain fall was another factor to influence the changing of soil water in potato based rotation field. When annual rainfall was less than $200 \mathrm{~mm}$, dry soil layer developed into the deeper soil both in spring maize field and in broomcorn millet field. When annual rainfall was more than $400 \mathrm{~mm}$, soil water recovered in $0-1.5 \mathrm{~m}$ soil both in foxtail millet field and in potato field. When annual rainfall was more than $500 \mathrm{~mm}$, soil water recovered in $0-1.0 \mathrm{~m}$ soil both in spring maize field and in broomcorn millet field.

\section{Discussion}

Rotation system can help break pest cycles, reduce pesticide use, and help control weeds [8]. In addition, rotation systems that include cereals can help improve soil organic matter level, thereby improve soil structure and productivity [9]. Results of this paper showed potato yield increased with the reduction of potato frequency in rotation system. Mean potato yield of group A was the highest with the value of $6.84 \mathrm{t} / \mathrm{hm}^{2}$, group C was the lowest with the value of $5.38 \mathrm{t} / \mathrm{hm}^{2}$. Jatoe et al. reported that rotating other crops with potato reduced farm returns above variable costs in potato based rotation system [6]. Our results indicated that farmer's gross income increased, when the frequency of potato decreased in the potato based rotation sequence. Mean gross income of group A was the highest, while group $\mathrm{C}$ was the lowest.

Depth and distribution character of root in soil results the different capacity of different crops to use soil water, and therefore results the different ability of different potato based rotation system to use soil water [10]. Results of simulated soil water showed, within group $\mathrm{B}$, available soil water of FBP was the highest, with the value of $1073 \mathrm{~mm}$; MFP was the second $(1010 \mathrm{~mm})$, and MBP was the third $(1008 \mathrm{~mm})$, MMP was the lowest $(981 \mathrm{~mm})$. Considering only from sustainable use of soil water, foxtail millet was the best crop to rotate with potato, and Broomcorn millet was the second. However table 3 showed, as a preceding crop, spring maize was the best crop, and foxtail millet was the second to increase potato yield. This may be a result of nutrition cycle, pest cycle and fungi development from preceding crops to potato within a rotation sequence [11]. 
To determine whether one rotation system was a best and sustainable cropping system, economic factor and environmental factor must be considered simultaneously. Soil water, was one of the key environmental factors to influence the sustainable development of agriculture in the arid regions of the Loess Plateau [12]. Jatoe et al. believed that rotation length, rotation sequence and crop specie together results the effect of rotation on environment and famer's income of potato based agricultural system [6]. Results of this paper showed, 1) FP and MPFP rotation system was better to produce more food for the farmer; 2) MP, FP and MPFP was better to increase farmer's gross income; 3) MP, FP, MPFP and FBP was better to utilize soil water sustainably. Considering from food production, sustainable utilization of soil water and gross income together, FP and MPFP rotation system was the better potato based rotation system for famers in the arid region of the Loess Plateau.

\section{Conclusion}

1) By comparing, spring maize was better to increase potato yield, however it used more water than foxtail millet and broomcorn millet; Foxtail millet was better to sustainable use of soil water, however its impacts on potato yield were depended on its sequence in potato based rotation system.

2) Spring maize/potato was not a sustainable potato based rotation system in the arid region of the Loess Plateau, foxtail millet/potato and spring maize/potato/foxtail millet/potato were two better rotation systems to use soil water sustainably and to increase farmer's gross income for a long period.

Acknowledgement. This study was sponsored by the Foundation of SWUST university for new teachers with doctor degree (No. 11zx7140). We are grateful to Wu-Qiang Li who had provided many information about potato production in the northern region of Shaanxi Province.

\section{References}

1. Wang, X.C., Li, J.: Evaluation of crop yield and soil water estimates using the EPIC model for the Loess Plateau of China. Mathematical and Computer Modeling 51, 1390-1397 (2010)

2. Statistics Bureau of Shaanxi Province: Statistical yearbook of Shaanxi Province of 2011, pp. 314-336. China Statistic Press, Beijing (2012)

3. Liu, P.S., Jia, Z.K., Li, J., Wang, J.P., Han, Q.F.: Effects of different alfalfa-crop rotation patterns on water recovery of degradation alfalfa grassland. Transactions of the CSAE 26(2), 95-102 (2010)

4. Li, J., Wang, L.X., Shao, M.A., Fan, T.L.: Simulation of autumn grain crop productive potential on Loess Plateau region of China. Journal of Northwest Sci.-Tech. University of Agriculture and Forest (Nature Science Edition) 29(5), 56-60 (2001) 
5. Wang, X.L., Chen, M.C., Li, F.M., Li, Y.J.: Effects of additional water and increased soil temperature on potato yields in Plastic-covered Ridge Rainwater-harvesting system. Agricultural Research in the Arid Area 25(3), 11-16 (2007)

6. Jatoe, J.B.D., Emmanuel, K.Y., Alfons, W., Clark, J.S.: Economic and environmental impacts of introducing land use policies and rotations on Prince Edward Island potato farms. Land Use Policy 25(3), 309-319 (2008)

7. Li, J., Chen, B., Li, X.F., Zhao, Y.J., Ciren, Y.J., Hu, W., Jiang, B., Cheng, J.M., Shao, M.A.: Effects of deep soil desiccation on artificial forestlands in different vegetation zones on the Loess Plateau of China. Acta Ecologica Sinica 28(4), 1429-1445 (2008)

8. Edward, B., Robert, P.L., Stellos, T., Erich, S.M., Andrei, A., Gary, S., Andrew, L., Serena, D.G.: Compost, rapeseed rotation and bio-control agents significantly impact soil microbial communities in organic and conventional potato production systems. Applied Soil Ecology 52, 29-41 (2012)

9. Nelson, K.L., Lynch, D.H., Boiteau, G.: Assessment of changes in soil health throughout organic potato rotation sequences. Agriculture, Ecosystems and Environment 131, 220-228 (2009)

10. Xiang, H.T., Feng, N.J., Du, J.D., Ma, G.S., Liu, B., Zheng, D.F.: Effects of plant growth regulators on physiological and biochemical characteristics of potato roots. Plant Nutrition and Fertilizer Science 15(6), 1481-1485 (2009)

11. Peters, R.D., Sturz, A.V., Carter, M.R., Sanderson, J.B.: Developing disease-suppressive soils through crop rotation and tillage management practices. Soil \& Tillage Research 72 , 181-192 (2003)

12. Chen, L.D., Huang, Z.L., Gong, J., Fu, B.J., Huang, Y.L.: The effect of land cover/vegetation on soil water dynamic in the hilly area of the loess plateau, China. Catena 70(2), 200-208 (2007) 